\title{
Building Integrated Geomechanical and Seismic Data Models for the Brazilian Pre-Salt Reservoirs Development, Examples in the Santos Basin
}

Talles Barsanti Meneguim ${ }^{1,2}$, Thelson Luiz Pinheiro de Almeida ${ }^{1}$, Renata dos Santos Giacomel ${ }^{1}$, Viviane Kotani Shimizu ${ }^{1}$, Antonio M. Nabuco Tartarini ${ }^{1}$, Alexandre Rodrigo Maul ${ }^{1}$, Raquel Quadros Velloso², ${ }^{1}$ Petrobras S.A., ${ }^{2}$ PUC-RJ

Copyright 2021, SBGf - Sociedade Brasileira de Geofísica

This paper was prepared for presentation during the $17^{\text {th }}$ International Congress of the Brazilian Geophysical Society held in Rio de Janeiro, Brazil, 16-19 August 2021.

Contents of this paper were reviewed by the Technical Committee of the $17^{\text {th }}$ International Congress of the Brazilian Geophysical Society and do not necessarily represent any position of the SBGf, its officers or members. Electronic reproduction or storage of any part of this paper for commercial purposes without the written consent of the Brazilian Geophysical Society is prohibited.

\begin{abstract}
The occurrence of giant and supergiant hydrocarbon accumulations in the Brazilian pre-salt carbonate province, in the Santos Basin, indicates its economic relevance. The geotechnical complexity of these deep carbonatic reservoirs located in ultra-deep water column joined to the complexity in the overburden section demand to the drilling wells operation and the field's development, the combination effort with a detailed geomechanical characterization. In that context, despite being an indirect measurement, high definition (HD) seismic data allows us to add valuable content to geomechanical modeling. In this paper, using HD seismic data and existing drilled wells, we demonstrate how to improve the understanding of the geohazards into overburden: shallow-water flow sands, shallow gas sands, high plasticity soluble salts and how to estimate the static deformability properties in the reservoir section supporting the production of hydrocarbon fields.
\end{abstract}

\section{Introduction}

It is estimated that carbonate reservoirs contain more than $60 \%$ of the oil reserves and $40 \%$ of the gas reserves in the world (Schlumberger, 2007). The carbonate reservoirs of the Brazilian pre-salt province in the Santos Basin are deep reservoirs situated below TVDSS of -5000 $\mathrm{m}$ and are located in ultra-deep-water column of more than $-2200 \mathrm{~m}$. The offshore portion of the Santos Basin has a complex stratigraphic column above pre-salt carbonate reservoirs, and it is composed by a huge salt section that vary from few meters until close to $3000 \mathrm{~m}$ of thickness (Mohriak et al., 2012) and besides, important carbonatic rafts above this salt section, as well as intercalated siliciclastic deposits.

A relevant issue in such petroleum field development is how to keep the field's oil volume production and profits at same time as the security in seabed facilities, pipelines, platforms and environment is being guaranteed (Zoback, 2007). One of the most known attempt regarding this matter is the maintenance of pressure by fluid injection. Besides, some important subsurface geologic hazards must be addressed in the offshore Santos Basin are short-term events and these may occur during the drilling and completion wells phases: shallow-water flow (SWF) sands and shallow gas sands into post-salt section, highly creep behaviour soluble salts at salt section and high pore-pressured rocks at the reservoir section. These short-term effects are potentially responsible for pipe sticking causing the loss of project profit and risks to seabed facilities (Teixeira et al., 2017; Toribio et al., 2017; Meneguim et al., 2019; Meneguim, 2019). Others geomechanical risks are associated to long-term reservoir's production such as seabed subsidence, seal rock failure, post-salt faults/fractures reactivation and damage to wells casings (Costa \& Poiate Jr., 2009).

To model all these 3D complexities an integrated cooperated team-work involving many disciplines such as geophysics, geology, reservoir and well engineering is mandatory (Meneguim, 2019).

At this work we show how to use seismic-data and it burial-depth behaviour to model geohazards into post-salt section to enhance the pre-salt production. We demonstrate the coupling effects between soluble salts and compressional impedance (P-Impedance) in the saltsection, which enables us to model these salts adopting a seismic inversion methodology. Complementarily, in order to access the uncertainties in the static deformability properties estimative from dynamic seismic attributes in the reservoir, it was chosen three different dynamic vs. static equivalences. The $1^{\text {st }}$ and $2^{\text {nd }}$ equivalences are very well-known parameters coming from scientific journals (Lacy, 1996; Pandula, 2002) and the $3^{\text {rd }}$ one was obtained from mechanical tests carried out in the PUC's rock tests lab using roman travertine core samples as carbonate reservoirs mechanical analogues (Meneguim, $2019 b)$. It was observed a difference around $35 \%$ in the elasticity modulus estimative and close to $22 \%$ in the Poisson's ratio estimative when comparing the less rigid $3^{\text {rd }}$ equivalence to the most rigid $1^{\text {st }}$ equivalence.

Therefore, in our research we show the benefits to develop complex models as well as the risk mitigation in geomechanical analysis when integrating it to seismic information.

\section{Method}

First of all, in order to estimate the geohazards making use of seismic data into post-salt section the residual seismic pulse (wavelet) must be removed from seismic 
data. Below, figure 1 illustrates the normalized wavelets frequency spectrum throughout burial depth (Meneguim et al., 2019)

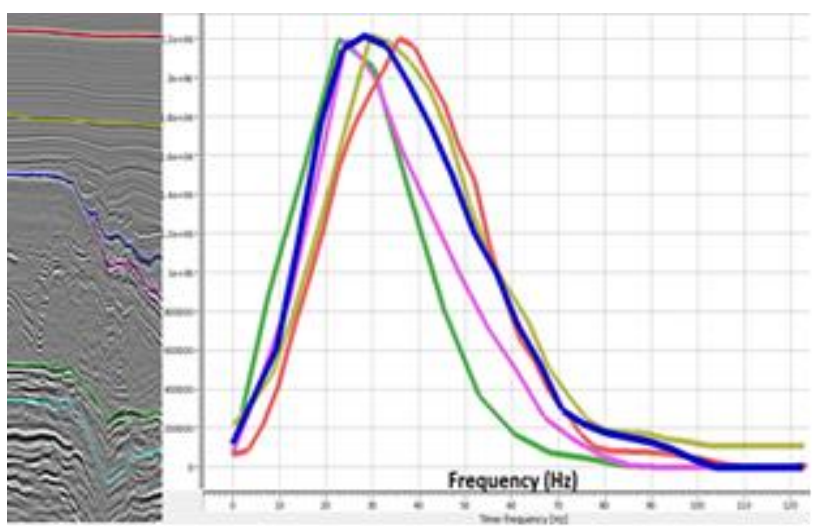

Figure 1: Normalized Wavelets Frequency Spectrum throughout the burial depth effect.

Next, in order to estimate geohazards using amplitude vs. offset (AVO) analysis, it were estimated the layers seismic attributes: Intercept and Gradient, used in AkiRichards 2 terms AVO equation (Rosa, 2018). For each layer restricted by a top and base picked seismic horizons it was interpreted a polygon referring to the desired anomalies. Figure 2 illustrates the desired anomalies for the first layer in the Fm. Marambaia, at the post-salt portion.

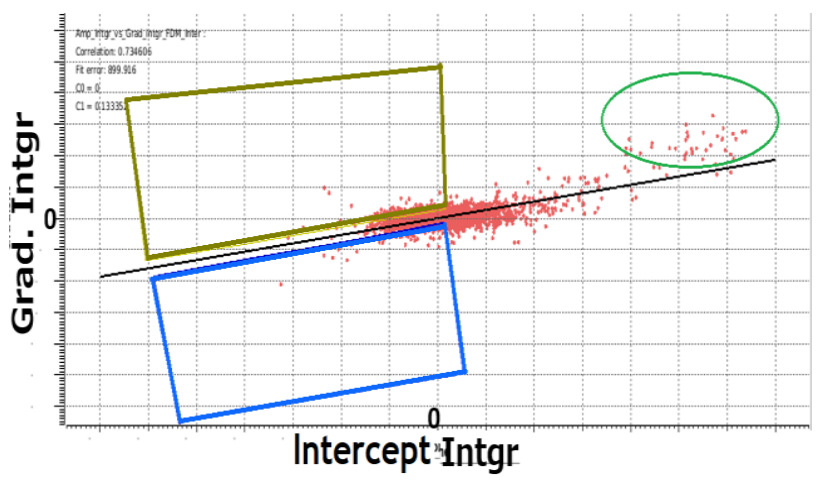

Figure 2: Crossplot Intercept vs. Gradient Seismic Attributes with Interpreted Anomalies for the Fm. Marambaia, shallow at the post-salt portion.

In figure 2 it is showed the background (black straight line) and we refer to this background the anomalies inside yellow polygon as being type shallow-water flow (SWF) high porosity sands; that the anomalies inside blue polygon as type of shallow gas high porosity sands and the anomalies inside green balloon as type of the unconsolidated and highly hydrated mud sediment at seabed.
At the salt section (Fm. Ariri) we use another approach, in that case adopting probability density functions (PDF), taking the drilled wells. Figure 3 illustrates the PDF from the borehole P-Impedance and cutting sample logs (Meneguim et al., 2015; Yamamoto et al., 2016). The relation between salt lithotypes/minerals and $P$. Impedance observed in figure 3 supports the salts forecast based on inverted P-Impedance from the seismic-data. Below, at figure 3 the worst salt in terms of mechanical behavior which is responsible for many warnings (Maul et al., 2018; Maul, 2020) in drilling wells operation is the yellow one tachyhydrite located in the lowest $\mathrm{P}$-Impedance values. That salt has a lot of water in it composition $\left(\mathrm{CaMg}_{2} \mathrm{Cl}_{6} \cdot 12 \mathrm{H}_{2} \mathrm{O}\right)$ and exhibits a highly creep behaviour.

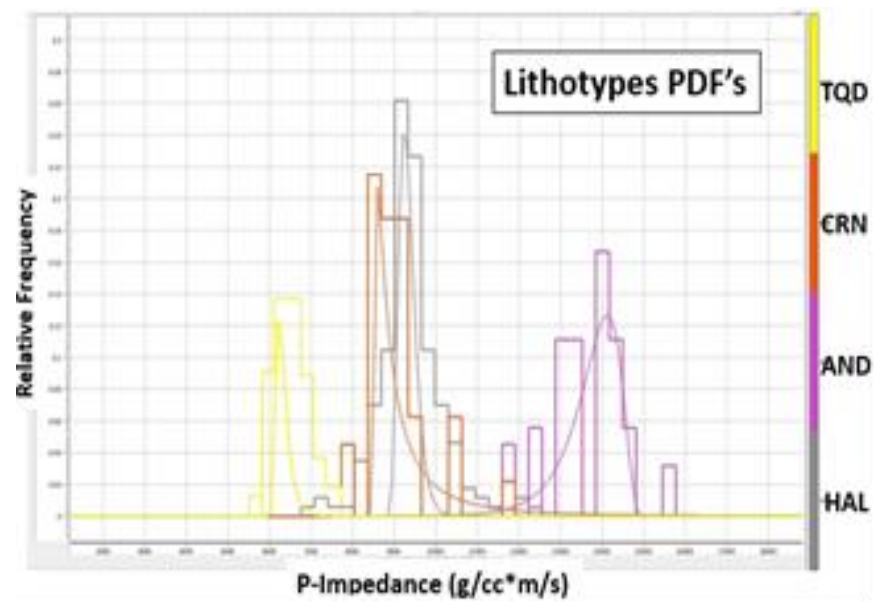

Figure 3: P-Impedance Wells-Log Histogram for each salt rock/mineral (halite in gray, anhydrite in purple, carnallite in red and tachyhydrite in yellow). The Gaussians Probability Density Functions for each salt mineral are the gaussian curves.

At the pre-salt reservoir section it was performed a deterministic model-based seismic inversion for dynamic $\mathrm{P}$ and S-Impedance.

As per our understanding, it is also essential to perform the seismic-geomechanical integration the equivalence involving dynamic deformability properties estimated from seismic data and the static deformability properties, which delivery reliable inputs for the long-term reservoir management.

To face the uncertainty analysis, which involves the static deformability properties estimative at the pre-salt reservoir, the Fm. Barra Velha, it was conducted a simultaneous hydrostatic compression test in the PUC's rock tests lab using a dry roman travertine block as a mechanical analogue.

Figure 4 illustrates the roman travertine block and the arrangement to the simultaneous hydrostatic compression test (Meneguim, 2019). 


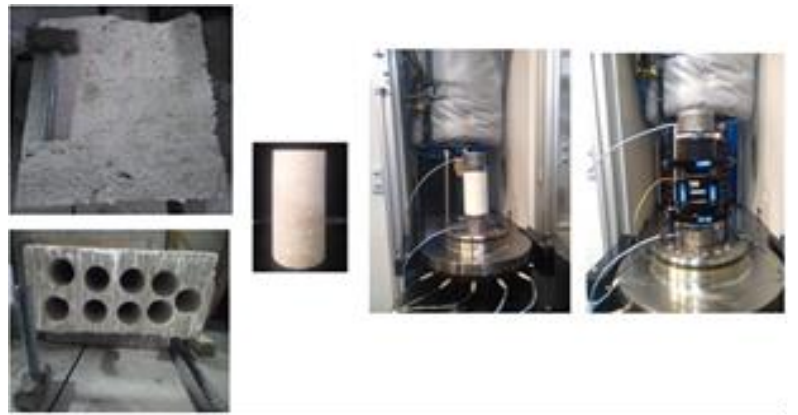

Figure 4: From left to right the roman travertine block, an extracted sample (plug), this same sample inside the compression press equipment and the once again the same sample, in which was added the strain gages.

Next figure (Figure 5), illustrates an ultrasonic-P pulse traveling through the travertine sample while it was compressed and the picked first break mark (red) corresponding to P-wave arrival time (Morschbacher et al., 2010; Meneguim, 2019).

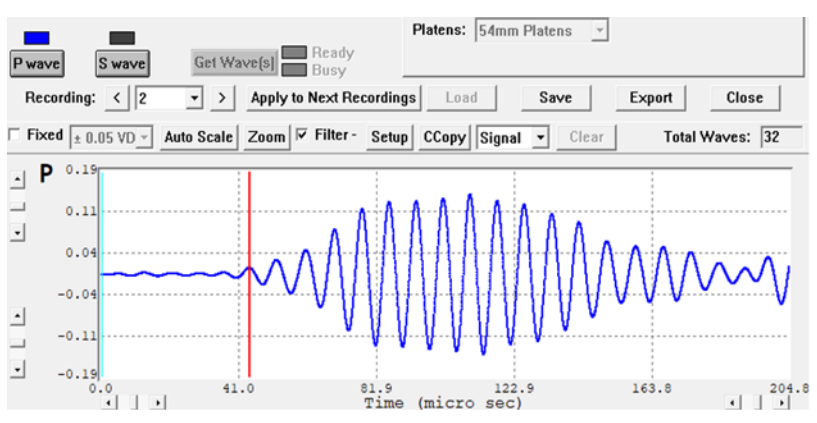

Figure 5: Ultrasonic- $P$ pulse traveling through the travertine sample at a given time of the hydrostatic compression test. Red line is the picked $P$-wave, corresponding to the first arrival time mark.

The obtained dynamic vs. static modulus equivalence for the simultaneous hydrostatic compression test done in PUC's rock tests lab is exhibited in figure 6 .

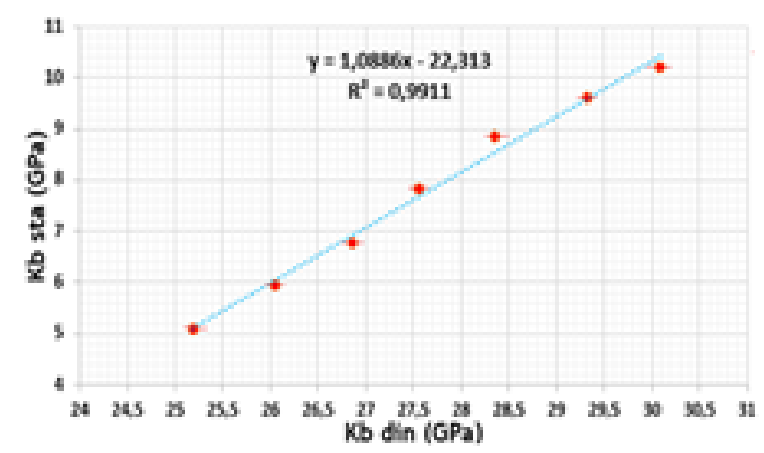

Figure 6: Dynamic vs. Static Equivalence for volumetric compressibility modulus obtained in PUC's rock tests lab for dry travertine sample used as mechanical analogue for the Fm. Barra Velha (the pre-salt reservoir analyzed in this study).

Below we present the resulting dynamic vs. static equivalence for the volumetric compressibility modulus that was obtained from the PUC's rock tests lab.

$$
K_{B} s t a=1,089 K_{B} \text { dyn }-22,313(\mathrm{GPa})
$$

In figure 7 we exhibit the three static vs. dynamic equivalences mentioned in the introduction section, for the elasticity modulus in order to access the uncertainties in the static deformability properties estimative for the presalt portion.

\begin{tabular}{|c|c|}
\hline $1^{\text {st }}$ & $E_{\text {sta }}=0,77 E_{d y n}+5854,12(\mathrm{~Pa})$ \\
Equivalence & (Pandula, 2002) \\
\hline $2^{\text {nd }}$ & $E_{\text {sta }}=0,478 E_{d y n}^{1,029}(\mathrm{GPa})$ \\
Equivalence & $($ Lacy, 1996) \\
\hline $3^{\text {rd }}$ & $E_{\text {sta }}=1,09 E_{\text {dyn }}-22,31(\mathrm{GPa})$ \\
Equivalence & (PUC's Lab) \\
\hline
\end{tabular}

Figure 7: The three equivalences for drained rocks used as dynamic vs. static elasticity modulus equivalence in the Brazilian pre-salt, Santos Basin.

\section{Results}

At post-salt section we obtain a 3D seismic-classes model focusing in the most relevant geotechnical hazards coupled with anomalies in some seismic attributes: intercept and gradient as presented in figure 2 .

Below, at figure 8, we illustrate that 3D seismic-classes model at post-salt section: light green represent background claystone, light yellow is type shallow water flow porous sands, gold yellow is type shallow gas porous sands, red represents background sands, dark green represents shale and blue represents hard marl.

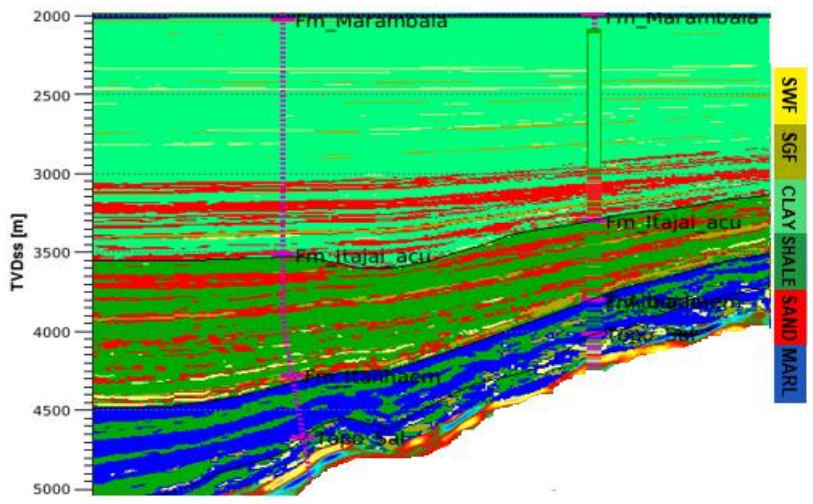

Figure 8: 3D seismic-classes at post-salt section coupled to geotechnical hazards 
At figure 8, the well situated at the right side is a drilled well used to control and calibrate the 3D seismic-classes model. And next, at figure 9 , we illustrate a detailed geological forecast for the well location at left side in figure 8.

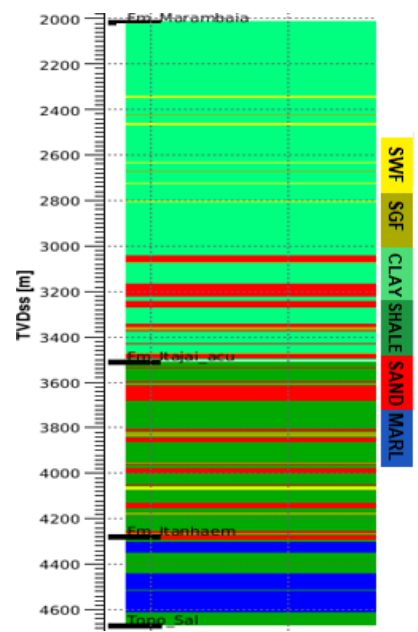

Figure 9: The detailed geological forecast focusing in the main geotechnical hazards and obtained through seismicattributes (extracted from the result presented in figure 8).

At the salt section we obtain a 3D seismic-classes model from seismically inverted $\mathrm{P}$-Impedance making use of the PDF for the salts' classification, as illustrated in figure 3 , focusing into detect the highly creep behavior and soluble salt (tachyhydrite) since it generally causes the most relevant geotechnical hazards there.

Below, figure 10, we illustrate the "3D" seismic-classes model at salt section delivering a new forecast: gray represents the background salt halite, purple represent the hard and insoluble salt (anhydrite) and gold yellow represents the tachyhydrite.

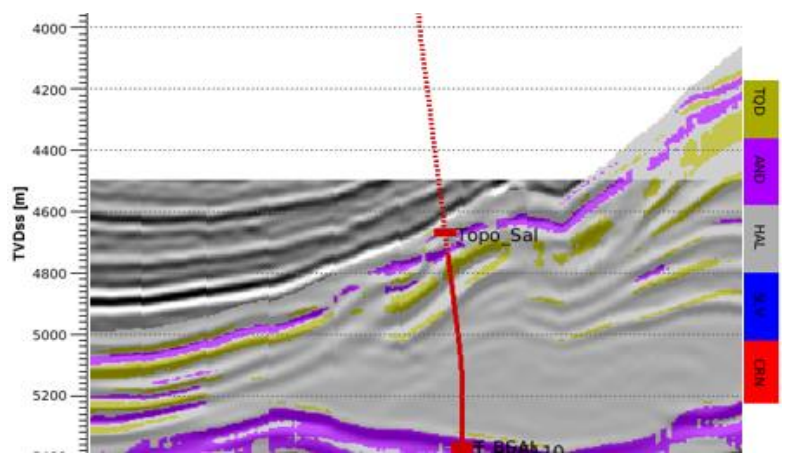

Figure 10: $3 D$ seismic classes at salt section.

Next, in figure 11, we illustrate the whole geological forecast for the well location at center and the seismic information used in this study.

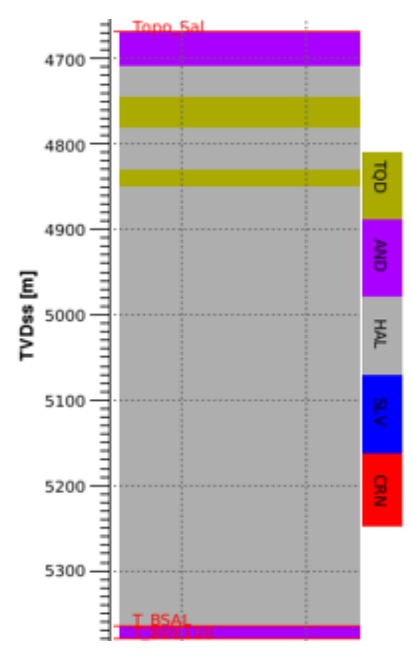

Figure 11: The detailed geological forecast focusing in the main geotechnical hazards at salt section and obtained through seismically inverted P-Impedance.

At the pre-salt reservoir section, taking the seismically inverted P and S-Impedance it were directly computed the dynamic deformability properties for saturated rock frame using the elasticity theory (Rosa, 2018).

Below, at figure 12, is exhibited for the elasticity modulus, in another analyzed well-location, the dynamic seismically obtained (in black color), the static modulus obtained from $1^{\text {st }}$ equivalence (in blue color), $2^{\text {nd }}$ equivalence (in green color) and the $3^{\text {rd }}$ equivalence (in red color). On this way we touch the uncertainty analysis involving the static deformability properties estimative at reservoir.

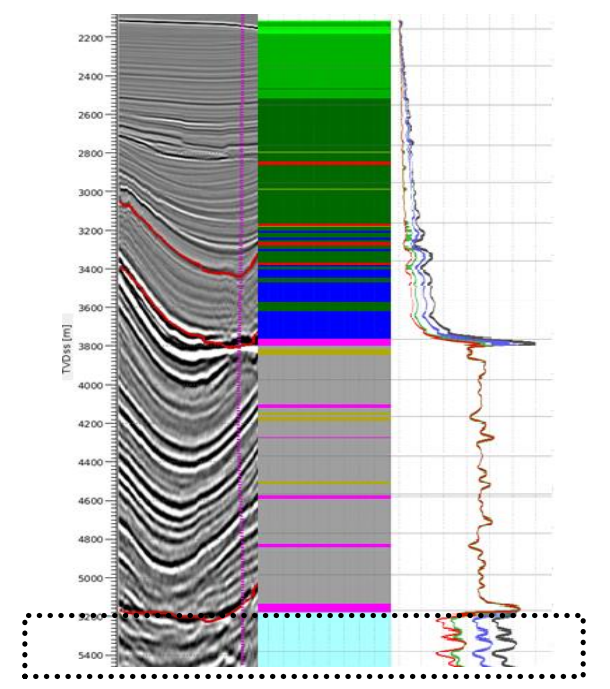

Figure 12: Elasticity Modulus for saturated rock frame at a given well-location. Dynamic (Black color), StaticEquivalence 1 (Blue color), Static-Equivalence 2 (Green color) and Static-Equivalence 3 (Red color).

The dashed rectangle on the bottom in figure 12 correspond to the reservoir. 
Since the three equivalences presented in figure 7 are for dry rocks, we used Gassmann fluid substitution method (Smith et al., 2003) to consider fluid effect in the elasticity modulus for saturated rock frame showed in figure 12.

Analyzing the three mentioned equivalences for the dynamic-static equivalence it was observed that the static elasticity modulus varies up to $35 \%$ in the reservoir from the hardest ( $1^{\text {st }}$ equivalence) to the softest one $\left(3^{\text {rd }}\right.$ equivalence) as showed in figure 12. It was also obtained that the Poisson coefficient varies up to $22 \%$ and BiotWillis coefficient varies up to $15 \%$.

The scenario 1 (Pandula, 2002) was the hardest scenario modelled and it is probably appropriate to cemented and low porosity rocks. The PUC's Lab Rock test equivalence (scenario 3) was the softest one since the roman travertine samples had a high porosity and some dissolutions and it is probably appropriate to high porosity or even karst systems. Scenario 2 (Lacy, 1996) behaves as an intermediate scenario in terms of deformability properties.

\section{Conclusions}

At this work it was showed some valuable content seismic data can add to build a complex geomechanical model.

At post-salt and salt section it was possible to model some important geotechnical hazards taking into account the burial depth effect in seismic data. Still at the post-salt portion, focusing on the SWF (shallow water flow) and SGF (shallow gas flow) high porosity sands forecast and their connection to seismic attributes: intercept and gradient in the AVO analysis.

At the salt section, focusing on the high creep salt behaviour: tachyhydrite and it connections to the seismically inverted $\mathrm{P}$-Impedance.

Finally for the three static vs. dynamic equivalences relations involving modulus of elasticity it was possible to touch the uncertainties issue at pre-salt reservoir, in the Santos Basin. Comparing the three scenarios we observe that the static elasticity modulus varies up to $35 \%$, the static Poisson's ratio varies up to $22 \%$ and the Biot-Willis coefficient varies up to $15 \%$.

It is argued at this work that $1^{\text {st }}$ equivalence was the hardest and it is probably appropriate to cemented and low porosity rocks. The $3^{\text {rd }}$ equivalence was the softest one and it is probably appropriate to high porosity or even karst systems. The $2^{\text {nd }}$ equivalence behaves as an intermediate equivalence in terms of deformability properties.

\section{Acknowledgments}

The authors would like to thank Petrobras for the permission to publish this work. Especially thanks to the geologist Bruno Pinheiro Pires and to the geophysicist Julio Justen, from Petrobras for their support in the PUC's rock tests lab.

\section{References}

Costa, A.M. \& Poiate JR, E. 2009. Rocha salina na indústria do petróleo: aspectos relacionados à reologia e à perfuração de rochas salinas. In: Mohriak, W, Szatmari, P. \& Anjos, S.M.C. (Eds.). Sal-Geologia e TectônicaExemplos nas Bacias Brasileiras. São Paulo, SP, Brazil: Beca Edições Ltda., p. 362-385.

Lacy, L.L. 1996. Dynamic Rock Mechanics Testing for Optimized Fracture Designs. SPE paper 38716 presented at the 1997 SPE Ann. Tech. Conf. \& Exhib. held in San Antonio, Texas, USA. 5-8 October.

Maul, A. 2020. Caracterização Sísmica da Seção Evaporítica Salina e suas Aplicações nos Projetos de Exploração, Desenvolvimento e Produção de Hidrocarbonetos. Doctor's Thesis. UFF. Niterói, RJ, Brazil.

Maul, A., Cetale, M.A. \& Silva, C.G. 2018. Few Considerations, Warnings and Benefits for the E\&P Industry when Incorporating Stratifications inside Salt Sections. Brazilian Journal of Geophysics, 36(4): 461477. doi: 10.22564/rbgf.v36i4.1981.

Meneguim, T.B., Mendes, S.C., Maul, A.R., Fernandes, L.F., Farias, M.G. \& González G. 2015. Combining seismic facies analysis and well Information to guide new interval velocity models for a Pre-Salt study, Santos Basin, Brazil. In: 14th International Congress of the Brazilian Geophysical Society, Brazilian Geophysical Society.

Doi: 10.1190/sbgf2015-271.

Meneguim, T.B. 2019. Integração Sísmica-Geomecânica no Pré-Sal Brasileiro, Bacia de Santos. Tese (Mestrado em Geotecnia) - Departamento de Engenharia Civil e Ambiental, Pontifícia Universidade Católica do Rio de Janeiro.

Meneguim, T.B., Velloso, R., Tartarini, A., Yamamoto, T., Queiroz, L. \& Almeida, M. 2019. Seismic Geomechanical Integration in the Brazilian Pre-Salt, Santos Basin In: International Congress of the Brazilian Geophysical Society \& Expogef, Rio de Janeiro. Proceedings of the 16th International Congress of the Brazilian Geophysical Society \& Expogef.

Mohriak, W.U., Szatmari, P. \& Anjos, S. 2012. Salt: geology and tectonics of selected Brazilian basins in their global context. In: Alsop, G.I., Archer, S.G., Hartley, A.J., Grant, N.T. \& Hodgkinson, R. (Eds.). Salt tectonics, sediments and prospectivity. Geological Society, London, Special Publications, 363, 131-158. https://doi.org/10.1144/sp363.7.

Morschbacher, M.J., Vasquez, G.F. \& Justen, J.C.R. 2010. Metodologias de estimativa das velocidades sísmicas em ensaios de laboratório. 40 Simpósio Brasileiro da Sociedade Brasileira de Geofísica, Brasília. 
Pandula, B. \& Mockovčiaková, A. 2002. Study of the Relation between the Static and Dynamic Moduli of Rocks.

Rosa, A.L.R. 2018. The seismic signal and its meaning. SEG. 788 pp. https://doi.org/10.1190/1.9781560803348.

Schlumberger 2007. Carbonate Reservoirs Market Analysis and World Energy Outlook 2006.

Smith, M.T., Sondergeld, H.C. \& Rai, S.R. 2003. Gassmann fluid substitution: A tutorial. Geophysics, Vol 68, p. 430-440. http://10.1190/1.1567211.

Teixeira, L, Gobatto, F, Maul, A, Cruz, N.M. Gonçalves, C. \& Laquini. 2017. Rock Physics and Seismic Inversion to identify stratification within salt section supporting velocity, facies modeling and geomechanical analysis. In: 15th International Congress of the Brazilian Geophysical Society, Rio de Janeiro, RJ, Brazil, p. 5-10. Brazilian Geophysical Society.

https://doi.org/10.1190/sbgf2017-002.

Toríbio, T., Queiroz, L.E., Teixeira, L., Yamamoto, T., Meneguim, T, Leonardo, L.M., Cortez, M., Relvas, M.T., Moliterno, A.M., Tartarini, A. \& Maul, A. 2017. Characterizing Evaporitic Section and Geomechanical Properties Using Seismic Inversion, a Case Study for Santos Basin. In: 15th International Congress of the Brazilian Geophysical Society, Brazilian Geophysical Society.Doi:10.1190/sbgf2017-226. 2017.

Yamamoto, T., Maul, A., Born, E., Gobatto, F., Campos, M.T. \& Gonzáles, M. 2016. Incorporação de Estratificações Salíferas na Modelagem de Velocidade de uma Jazida da Bacia de Santos. VII Simpósio Brasileiro de Geofísica, Ouro Preto - MG.

Zoback, D.M. 2007. Reservoir Geomechanics. Cambridge: Cambridge University Press. https://doi.org/10.1017/CBO9780511586477 